\title{
Tuberculoma intracraneal simulando neoplasia maligna. Caso clinico y revision de
}

\section{la literatura}

\author{
J.A. Álvarez-Salgado; J.A. Ruiz-Ginés; C.D. Fuentes-Ventura; A.G. Gonzales-Sejas; J.M. Belinchón de Diego; F. \\ González-Llanos Fernández de Mesa y A. Rodríguez de Lope-Llorca
}

Servicio de Neurocirugía. Servicio de Anatomía Patológica. Hospital Virgen de la Salud. Toledo.

\section{Resumen}

Introducción. Las manifestaciones extrapulmonares de la tuberculosis (TBC) que afectan al Sistema Nervioso Central (SNC) por diseminación hematógena no son una entidad infrecuente. El tuberculoma es un proceso inflamatorio granulomatoso que radiológicamente, en raras ocasiones, simula un tumor maligno. A continuación se expone el caso y la revisión de la literatura sobre un tuberculoma gigante frontal derecho que simula un tumor maligno.

Caso clínico. Mujer de 64 años de edad que ingresa en nuestro hospital tras varias semanas de cefalea acompañada de trastornos del comportamiento y discreta hemiparesia derecha. Las imágenes de RMN cerebral mostraban una lesión frontal izquierda sugestiva de tumor maligno. Las imágenes de TAC mostraban afectación ósea. En la cirugía se observó una lesión nodular y avascular con posterior confirmación anatomopatológica de inflamación granulomatosa altamente sugestiva de tuberculoma. La PCR frente a Mycobacterium tuberculosis complex confirmó el diagnóstico. Los tuberculomas intracraneales son una forma poco frecuente de tuberculosis del SNC. EI pronóstico está relacionado con el diagnóstico precoz, el grado de resección quirúrgica $\mathbf{y}$ el tratamiento complementario con fármacos antituberculosos.

Conclusiones. Exponemos una presentación poco frecuente de un tuberculoma cerebral gigante que mediante RMN nos hizo pensar en un tumor maligno. La TAC mostró la infiltración ósea. El diagnóstico definitivo puede establecerse en base a los resultados anatomopatológicos de la biopsia cerebral o mediante la detección del ADN de Mycobacterium tuberculosis por PCR.

PALABRAS CLAVE. Tuberculoma. Neurocirugía. Infiltración ósea. PCR

Recibido: 7-09-10, Aceptado: 8-05-11
Intracranial tuberculoma simulating a malignant tumor: Case report and literature review

Summary

Introduction. Extrapulmonary manifestations of tuberculosis involving the central nervous system (CNS) due to haematogenous spread are not a rare entity. Tuberculoma is a granulomatous inflammatory process mimicking in rare occasions a malignant neoplasm radiologically. The authors report a case of a giant right frontal tuberculoma mimicking a malignant tumor and review the literature.

Case report. A sixtyfour-year-old women with several weeks of headache and behavior alterations admitted at the hospital with light right hemiparesis. The MRI showed a left frontal tumor suggestive of a malignant tumor. CT showed bone infiltration. At surgery, a nodular, avascular lesion was found and pathological examination confirmed granulomatous inflammation suspecting tuberculoma. Mycobacterium tuberculosis complex-specific PCR assay confirmed diagnosis. Intracranial tuberculoma is an uncommon variety of central nervous system tuberculosis. The prognosis is related to the early diagnosis, surgical resection and the complementary antituberculosis treatment.

Conclusions. We present the unusual presentation of a giant brain tuberculoma which MRI led us to believe was a malignant tumor. Computed Tomography revealed bone infiltration. Positive diagnosis could be established on the basis of the pathology results of a brain biopsy or detection of DNA of Mycobacterium tuberculosis in the PCR study

KEY WORDS. Tuberculoma. Brain. Surgery. Bone infiltration. PCR.

Introducción

La tuberculosis (TBC) tiene una incidencia anual varia- 
ble en función de la localización geográfica y oscila de unos 9 casos/100.000 en EE.UU. a unos 110 - 165 casos/100.000 habitantes en Asia y África ${ }^{8}$. La TBC del Sistema Nervioso Central (SNC) es una forma grave y devastadora de TBC extrapulmonar presente en aproximadamente un $6.3 \%$ de todos los pacientes con tuberculosis ${ }^{4}$, afectando con mayor frecuencia a pacientes en edad pediátrica y adultos con estados de inmunosupresión. Esta forma de la enfermedad tiene un riesgo de mortalidad de hasta un $3.2 \%$ de todas las muertes atribuibles a la tuberculosis en un estudio realizado en nuestro país entre los años 1970 y $1993^{6}$. La afectación del sistema nervioso central se manifiesta generalmente como meningitis tuberculosa y menos frecuentemente como encefalitis tuberculosa, tuberculoma intracraneal o espinal y absceso tuberculoso ${ }^{12}$.

El término tuberculoma es un concepto anatomopatológico, entendiéndose como tal a aquel conglomerado de focos de necrosis caseosa alojado en el parénquima cerebral que aparece como consecuencia de una diseminación hematógena reciente o tardía de bacilos tuberculosos. Radiológicamente son lesiones únicas generalmente pero en un $15-34 \%$ pueden ser múltiples y en un 10\% pueden estar asociadas a una meningitis tuberculosa ${ }^{13}$. En ocasiones cursan de forma silente y pueden simular una tumoración intraaxial de alto grado de malignidad ${ }^{7}$. Generalmente se manifiestan con signos y/o síntomas de déficit neurológico focal sin evidencia de enfermedad sistémica o inflamación meníngea. Presentamos el caso inusual de una paciente que debuta con una masa intracraneal con sospecha de neoplasia de características malignas.

\section{Caso clínico}

\section{Historia clínica y presentación inicial}

Se trata de una mujer de 64 años en tratamiento con diálisis por insuficiencia renal crónica, que presenta un cuadro de un mes de evolución de deterioro cognitivo, apatía, desorientación, lenguaje incoherente y debilidad generalizada que le impedía la deambulación. A la exploración la paciente estaba confusa y desorientada con tendencia al sueño y presentaba disfasia de predominio motor con discreta paresia $4 / 5$ en miembro superior derecho acompañada de debilidad generalizada. El hemograma no mostraba signos de infección. En el estudio con radiología simple de tórax se observó mínimo derrame pleural derecho sin alteraciones parenquimatosas ni adenopatías mediastínicas asociadas.

\section{Diagnóstico por imagen}

En los estudios de neuroimagen la TC cerebral mostraba una lesión ocupante de espacio frontal izquierdo, heterogénea, que realzaba contraste en anillo con importante edema perilesional comprimiendo el asta frontal del ventrículo lateral ipsilateral. En la ventana ósea en un corte se apreciaba infiltración ósea de la tabla interna y el diploe del hueso frontal. En estudio con RMN cerebral (ver figura 1) se apreció lesión de similares características siendo más llamativa la infiltración dural.

\section{Tratamiento quirúrgico}

Se realizó intervención con craneotomía frontal iz quierda apreciándose lesión abigarrada con destrucción de duramadre en el centro e invasión de tabla interna ósea. Tras la apertura de la duramadre se apreció importante edema cerebral procediéndose a la extirpación de la lesión de forma completa. El defecto dural se cerró con plastia reabsorbible de duramadre.

\section{Histología y microbiología}

En el estudio anatomo-patológico Hematoxilina- eosina se apreciaron granulomas en parénquima cerebral, con necrosis caseosa central, células gigantes multinucleadas tipo Langerhans, células epitelioides e infiltrado linfocitario perilesional (ver figura 2). Se realizó tinción de Ziehl- Neelsen de parte de la muestra enviada apreciándose infección por bacilos ácido-alcohol resistentes. Se remitió muestra para estudio con PCR obteniéndose el diagnóstico de confirmación de infección por Mycobacterium tuberculosis.

La tinción de Zhiel Neelsen mostró la existencia de bacilos ácido alcohol resistentes y el diagnóstico de confirmación se estableció mediante la detección del ADN de Mycobacterium tuberculosis en los preparados de tejido cerebral analizados.

\section{Curso clínico y evolución}

La evolución postoperatoria fue favorable iniciándose tratamiento antituberculoso con buena evolución posterior, sin presentar déficits neurológicos con control radiológico al año sin datos de recidiva.

\section{Discusión}

La adquisición de la infección por M. tuberculosis ocurre a través de la inhalación de gotas de vapor que contienen el bacilo, depositándose éste en el alveolo pulmonar. Una vez allí el bacilo interactúa con los macrófagos alveolares a través de diferentes receptores liberando numerosas citoquinas que intervienen en la respuesta inmune mediada por los linfocitos T-helper, formándose el granuloma. En fases tempranas de este proceso, antes de la contención de la infección, algunos bacilos pueden filtrarse en el sistema 


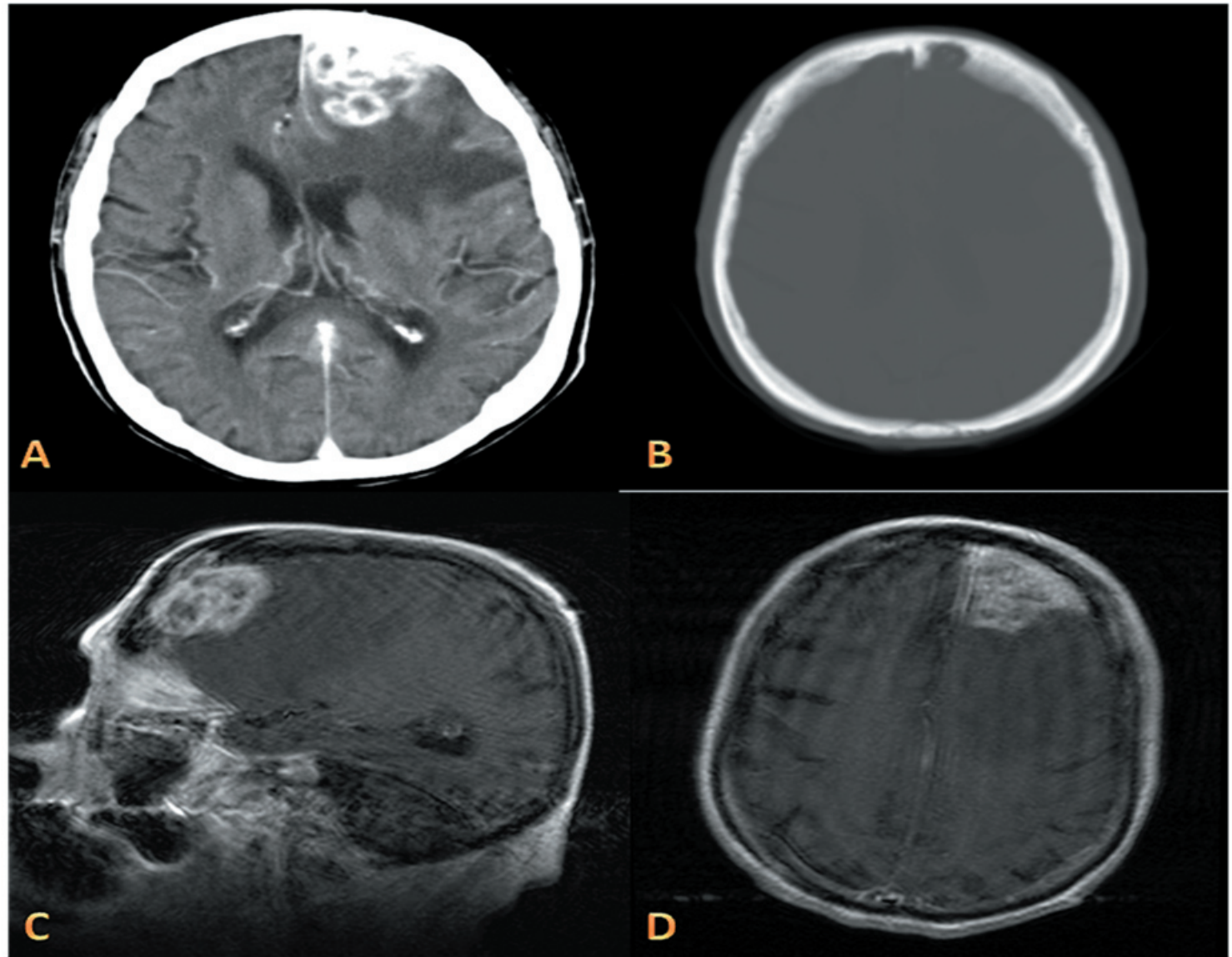

Figura 1. A. TAC cerebral con contraste: lesión frontal izquierda, heterogénea, que realza contraste en anillo con importante edema perilesional que comprime el asta frontal del ventrículo lateral ipsilateral. B. TAC craneal: infiltración ósea de la tabla interna y el diploe del hueso frontal. C y D. RMN cerebral (T1 con contraste axial y sagital): lesión de similares características siendo más llamativa la infiltración dural.
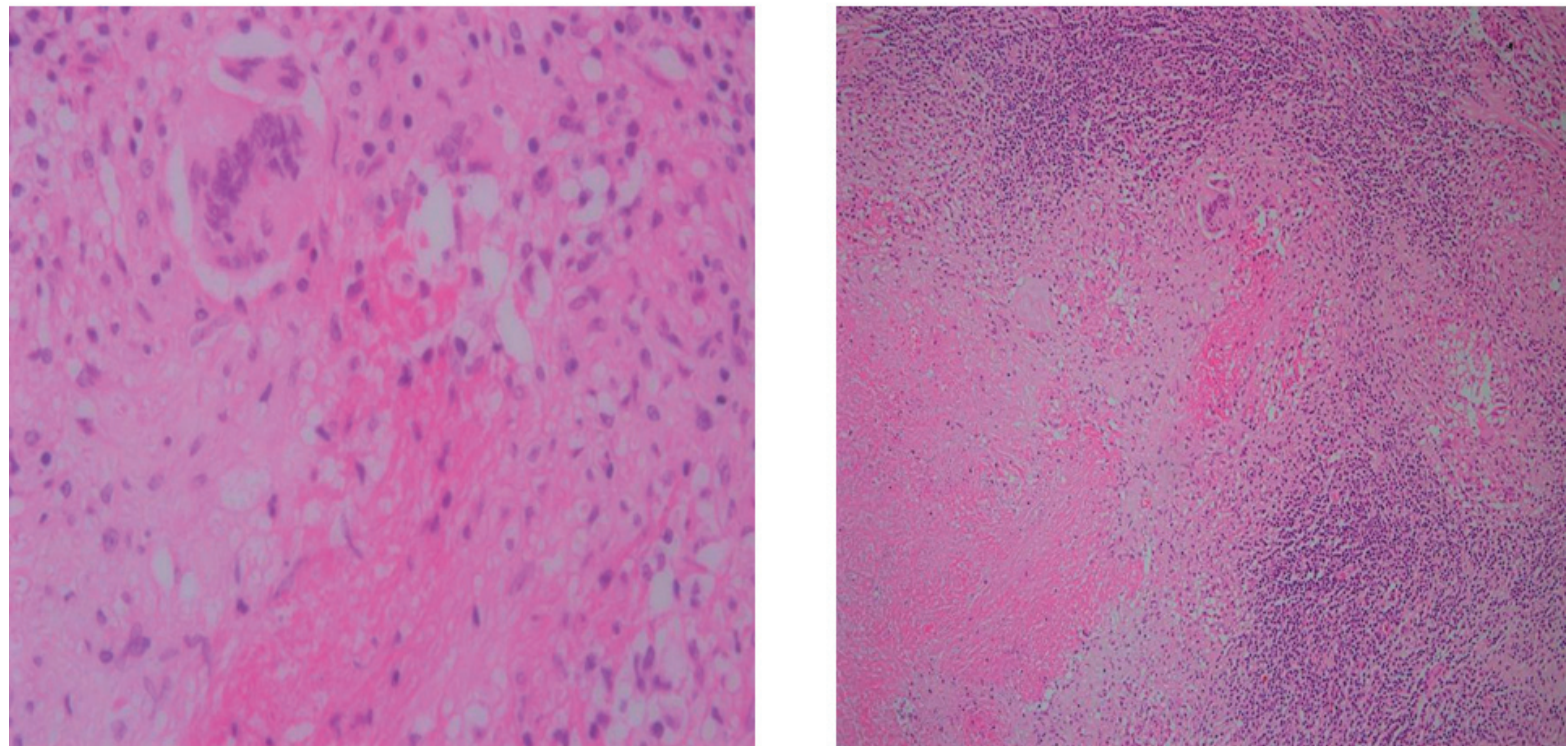

Figura 2. Hematoxilina-eosina: granuloma en parénquima cerebral, con necrosis caseosa central, células gigantes multinucleadas tipo Langerhans, células epitelioides e infiltrado linfocitario perilesional. 
de drenaje linfático y de allí diseminarse vía hematógena a diferentes regiones del organismo, generalmente zonas altamente oxigenadas como puede ser el cerebro. En el SNC la enfermedad comienza con el desarrollo de pequeños focos tuberculosos denominados focos de Rich, a nivel cerebral, medular o en meninges ${ }^{11}$. La localización de estos focos y la capacidad del sistema inmune de controlarlos determinará la manifestación de la enfermedad en el sistema nervioso como meningitis tuberculosa o menos frecuentemente como encefalitis tuberculosa, tuberculoma o absceso tuberculoso ${ }^{12}$.

Los tuberculomas o granulomas tuberculosos se generan sobre todo a nivel supratentorial en adultos inmunocompetentes, las áreas más frecuentes son los hemisferios cerebrales, sobre todo a nivel de lóbulos frontales, mientras que en los niños es el cerebelo ${ }^{2}$. La localización cortical y subcortical es típica. Los ventrículos cerebrales, hipófisis y el tronco del encéfalo son zonas menos frecuentes. Los tuberculomas suelen ser solitarios pero en un $10-35 \%$ de los casos pueden ser múltiples ${ }^{15}$. Un patrón miliar con innumerables pequeñas lesiones parenquimatosas es infrecuente, excepto en niños con meningitis tuberculosa. El tuberculoma en placa, descrito por primera vez en 1979 por Welchman, es más raro y puede presentarse como una lesión solitaria, focal, en placa globular o irregular, localizándose en relación con un surco y las meninges ${ }^{16}$.

El aspecto de los tuberculomas en la TC o RM depende de su estado evolutivo. Durante el estadío agudo la TC puede no mostrar más que un área hipodensa causada por cerebritis. Los tuberculomas inmaduros son iso o ligeramente hiperintensos en la TC sin contraste y muestran un realce anular, nodular o irregular tras la administración de contraste. A veces puede observarse una lesión con realce en anillo y un área central de realce o de calcificación conocido como el "signo de la diana". Sin embargo este signo es inespecífico ya que se puede presentar en otro tipo de infecciones como la neurocisticercosis. En el caso que presentamos podemos ver como en la figura 1 en la secuencia con TC se aprecia una zona de afectación ósea frontal izquierda con una zona de calcificación central aunque el denominado signo de la diana es típico en la localización intraparenquimatosa. En la RM, en secuencias ponderadas en T1 dan típicamente unas imágenes isointensas con una región central hiperintensa y un borde hipointenso en secuencias ponderadas T2, sin embargo el aspecto es variable según su estado evolutivo. En estadíos precoces aparece hipointenso en T2 respecto al tejido cerebral normal. En estados más evolucionados, la cápsula aparece con una isoseñal respecto a la sustancia gris y con una zona central de hiposeñal en el caso de haber necrosis caseosa o de hiperseñal cuando hay licuefacción central. La inyección de gadolinio puede producir un realce periférico anular o nodular. Las secuencias de imagen por difusión y espectroscopía también pueden ser útiles en la identificación de los distintos componentes de la lesión, mostrando por lo general un pico elevado de lípidos ${ }^{15}$.

Los tuberculomas con un patrón de crecimiento con implantación dural son raros y aquellos descritos tienen características radiológicas similares a los meningiomas con extensión transcraneal ${ }^{5}$. La paciente que presentamos es un caso inusual debido a la presentación insidiosa con trastorno del comportamiento y datos de hipertensión intracraneal. Los estudios con RM demostraron una lesión intracraneal con características neoplásicas, edema perifocal y destrucción ósea en el estudio con TC. Estas características de imagen aunque eran sugestivas de un tumor maligno dadas las características de la lesión ósea en la TC hicieron plantear la cirugía de forma más conservadora dada la localización frontal izquierda aunque posteriormente pudo realizarse una resección completa de la lesión.

El diagnóstico de TBC cerebral es complejo y se basa en hallazgos clínicos, bioquímicos/citológicos (en líquido cefalorraquídeo) y radiológicos. La confirmación bacteriológica aún sigue siendo negativa en un alto porcentaje de pacientes y las pruebas serológicas no gozan de suficiente especificidad y sensibilidad. Existen numerosos casos ya publicados de empleo de la PCR en líquido cefalorraquídeo para la obtención de diagnóstico definitivo. En nuestro caso se realizó el diagnóstico histológico confirmado posteriormente con PCR de muestras del tejido obtenido en la cirugía.

El tratamiento de los tuberculomas intracraneales ha sido controvertido durante años y aunque está universalmente aceptado que el tratamiento antibiótico combinado es esencial, no existe acuerdo sobre el régimen de drogas a seguir, la duración del tratamiento o el papel de la cirugía en el mismo ${ }^{8}$. La sociedad americana de cirugía torácica y el Centro de prevención y control de enfermedades recomiendan un tratamiento de 12 meses, extendiéndose a 18 meses si el paciente no recibe pirazinamida durante los primeros 2 meses de tratamiento ${ }^{4}$. El papel de la cirugía está en principio reservado para aquellos casos en los que existen datos de hipertensión intracraneal o para confirmación del diagnóstico de sospecha clínica con biopsia de la lesión. Sin embargo series publicadas como la de Poonnoose y colaboradores (ver tabla 1) señalan que la extirpación total se debe considerar también en aquellas lesiones situadas en regiones no elocuentes y accesibles del cerebro especialmente si son únicas o persisten a pesar del tratamiento antibiótico mantenido un periodo de tiempo razonable dado que la extensión de la resección quirúrgica puede afectar la tasa de resolución final ${ }^{9}$. Por otro lado hay que considerar que el tratamiento con tuberculostáticos no está exento de riesgos dado su alta hepatotoxicidad. En nuestro caso la indicación de la cirugía cumplía los criterios de ser una lesión con datos de hipertensión intracraneal y accesible, con bajo riesgo de producir secuelas postquirúrgicas tras la cirugía. La paciente 
Tabla 1

Tasas de resolución de tuberculomas al finalizar el tratamiento en diferentes series

\begin{tabular}{lcc}
\hline Serie/Año (Referencia) & Tiempo tratamiento (meses) & Pacientes con lesión residual \\
\hline Rajshekhar, 1995 (10) & 9 & $12 \%$ \\
\hline Awada, 1998 (1) & 12 & 0 \\
\hline Poonnose, 2003 (8) & 18 & $69.2 \%$ \\
\hline
\end{tabular}

posteriormente recibió tratamiento antituberculoso durante 12 meses con estudios radiológicos con RM sin datos de persistencia o recidiva de enfermedad.

\section{Conclusiones}

La afectación del SNC por tuberculosis con o sin manifestaciones extracerebrales puede ocurrir en forma de una lesión ocupante de espacio que en los estudios de imagen asemeje una neoplasia maligna. El análisis detallado de los estudios de imagen preoperatorios con identificación de lesiones que afecten infiltren el hueso craneal identifica aquellos casos sospechosos debiéndose incluir el tuberculoma entre las posibilidades diagnósticas especialmente en pacientes con estados de afectación del sistema inmunitario. El papel de la cirugía debe considerarse en aquellas lesiones accesibles y con datos de hipertensión intracraneal. La demostración de bacilos ácido-afílicos en ocasiones no es posible y el tratamiento debe iniciarse en base a criterios histológicos y de sospecha clínica. El estudio con PCR en el material extraído o incluso en LCR puede facilitarnos el diagnóstico definitivo.

\section{Bibliografía}

1. Awada, A., Daif, A.K., Pirani, M., Khan, M.Y., Memish, Z., Al Rajeh, S.: Evolution of brain tuberculomas under standard antituberculous treatment. J Neurol Sci. 1998: 156: 47-52.

2. Bayindir, C., Mete, O., Bilgic, B.: Retrospective study of 23 pathologically proven cases of central nervous system tuberculomas. Clin Neurol Neurosurg. 2006 Jun; 108: 353-357

3. Cardona, E., Molet, J., Oliver, B., Parés, P., Tresserras, P., Ortiz, N., Bartomeus, F.: Tuberculoma cerebral. A propósito de un caso. Neurocirugia 1995; 4: 319-321.

4. CDC. 2005. Extrapulmonary tuberculosis cases and percentages by site of disease: reporting areas, 2005. Centers for Disease Control and Prevention, Atlanta, GA. www.cdc.gov/ tb/surv/surv2005/PDF/table27.pdf.

5. Di Patre, P.L., Radziszewski, W., Martin, N.A., Brooks, A., Vinters, H.V. (2000): A meningioma-mimicking tumor caused by Mycobacterium avium complex in an immunocompromised patient. Am J Surg Pathol 24: 136-139.
6. Franco, J., Blanquer, R..: Mortality from tuberculosis in Spain from 1970 to 1993: Changes in epidemiological trends during the acquired immune-deficiency syndrome epidemic. Int. J. Tuberc. Lung Dis. 1998; 2: 663-669.

7. Giese, A., Kucinski, T., Hagel, C., Lohmann, F.: Intracranial tuberculomas mimicking a malignant disease in an immunocompetant patient. Acta Neurochir 2003; 145: 513-517

8. Poononoose, S.I., Rajshekhar, V.: Rate of resolution of histologically verified intracranial tuberculomas. Neurosurgery. 2003; 53: 873-878.

9. Poononoose, S.I., Singh, S., Rajshekhar, V.: Giant cerebellar tuberculoma mimicking a malignant tumour. Neuroradiology. 2004; 46: 136-139.

10. Rajshekhar, V., Chandy, M.J.: Short-course chemotherapy for intracranial tuberculomas. Tuber Lung Dis 1996; 77:295-296

11. Rock, R.B., Olin, M., Baker, C.A., Molitor, T.W., Peterson, P.K.: Central Nervous System Tuberculosis: Pathogenesis and Clinical Aspects. Clin Microbiol Rev. 2008; 21:243-261

12. Rom, W. N., and S. M. Garay. 2004. Tuberculosis, $2^{\text {nd }}$ ed. Lippincott Williams \& Wilkins, Philadelphia, PA).

13. Rosenblum, M.K., Bilbao, J.M., Ang, L.C.: Neuromuscular system, infectious disease. In: Rosai J, editor. Rosai and Ackerman's surgical pathology, 2, $9^{\text {th }}$ ed. Mosby; 2004. p. 2490-2191

14. Semlali, S., El Kharras, A., Mahi, M., Hsaini, Y., Benameur, M., Aziz, N., Chaouir, S., Akjouj, S.: Les aspects en imagerie de la tuberculose du systeme nerveux central. J Radiol 2008; 889: 209-220.

15. Wasay, M., Kheleani, B.A., Moolani, M.K., Zaheer, J., Pui, M., Hasan, S., et al.: Brain CT and MRI findings in 100 consecutive patients with intracranial tuberculomas. J Neuroimaging 2003; 13: 240-247

16. Welchman, J.M.: Computerized tomography of intracranial tuberculoma. Clin. Radiol 1979; 30: 567-573.

Álvarez-Salgado, J.A.; Ruiz-Ginés J.A.; Fuentes-Ventura, C.D.; Gonzales-Sejas, A.G.; Belinchón de Diego, J.M.; González-Llanos Fernádez de Mesa, F.; Rodríguez de Lope-Llorca, A.: Tuberculoma intracraneal simulando neoplasia maligna. Caso clinico y revision de la literatura. Neurocirugía 2011; 22: 600-604. 